\title{
Effect of Granulocyte and Granulocyte Macrophage Colony Stimulating Factors (G-CSF and GM-CSF) on Neonatal Neutrophil Functions
}

\author{
BARUCH WOLACH, RONIT GAVRIELI, AND AVISHALOM POMERANZ \\ Department of Pediatrics, the Pediatric Hematology Clinic and the Laboratory for Leukocyte Function, \\ Meir General Hospital, Kfar-Sava, Israel
}

\begin{abstract}
Although there are many studies on the effect of granulocyte and granulocyte-macrophage colony stimulating factors (G/GM$\mathrm{CSF}$ ) on adult neutrophil functions, there is little information regarding their influence on neonatal cells. We studied the in vitro effect of G/GM-CSF on neutrophil chemotaxis, polarization, and superoxide anion generation in 47 neonates compared with 35 adults. We found that G-CSF and GM-CSF significantly enhanced the chemotaxis of newborn infants' neutrophils, normalizing their chemotactic defect [from $35 \pm 7$ cells/field (mean $\pm \mathrm{SE}$ ) to $49 \pm 5$ cells/field with G-CSF, $p<0.05$ and to $55 \pm 4$ cells/field with GM-CSF, $p<0.001]$. It is notable that the maximal neutrophil response to the cytokines was observed particularly in the newborn infants with severe impairment in their chemotactic activity. Statistical analysis of the data showed a significant inverse correlation, which supported this observation $(r=-0.6, p<0.02$ for G-CSF; $r=-0.76, p<0.001$ for GM-CSF). The reduced polarization of neonatal compared with adult cells $[71 \pm 5 \%$ versus $86 \pm 2 \%$ (mean $\pm \mathrm{SE}$ ), $p<0.05]$, was corrected by CSF-priming (to $87 \pm 4 \%$ with G-CSF and to $92 \pm 2 \%$ with GM-CSF, $p<0.05)$. In addition, the neutrophil
\end{abstract}

\section{ABSTRACT}

superoxide generation was significantly improved in both groups following the CSF-priming. GM-CSF and G-CSF gave comparable results in all functions studied except that GM-CSF improved superoxide release to a greater extent. This study shows a significant improvement of the neonatal neutrophil functions following in vitro CSF-priming and contributes to a better understanding of the neonatal neutrophil behavior when treated with G/GM-CSF. (Pediatr Res 48: 369-373, 2000)

\[ \text { Abbreviations } \]
VLBW, very low birth weight
G-CSF, granulocyte colony stimulating factors
GM-CSF, granulocyte-macrophage colony stimulating factors
PMN, polymorphonuclear leukocytes
HBSS, Hanks' buffered salt solution
fMLP, N-formyl-methionyl-leucyl-phenylalanine
PVP, polyvinylpyrrolidone
GLM, general linear model
PMA, phorbol myristate acetate
NSP, neutrophil storage pool

Neonatal sepsis continues to be a major cause of morbidity and mortality in the nursery and the neonatal intensive care unit, particularly in the VLBW newborn infant $(1,2)$. Despite the aggressive supportive treatment and the appropriate use of antibiotics, the mortality rate remains high. New forms of adjunctive immunotherapy are needed. Neutropenia and depleted neutrophil storage pools have been found to be associated with neonatal bacterial sepsis and are predictive of a poor prognosis (3-6). Neutrophil functions were also reported to be impaired in newborn infants $(2$, 7-11).

Hematopoietic growth factors, G-CSF, and GM-CSF, are soluble glycoproteins that regulate the proliferation and differentiation of hematopoietic precursor cells (12-14). CSF have

Received June 8, 1999; accepted April 27, 2000.

Correspondence: B. Wolach, M.D., Department of Pediatrics, Pediatric Hematology Clinic, and the Laboratory for Leukocyte Function, Meir General Hospital, Kfar Sava, Israel, 44281. been found to exert functional effects on neonatal and adult neutrophils (15-23). Additionally, in adult neutrophils G-CSF and GM-CSF appear to have different profiles of activity (15, 19).

Hematopoietic CSF have been shown to improve the clinical condition of patients with neutropenias and to reduce the length of neutropenia following chemotherapy and bone marrow transplantation (24-29). In addition, because neonatal neutrophils have been found to produce less G-CSF than adults $(30-33)$, supportive therapy with hematopoietic growth factors has been used in an effort to improve quantitative and qualitative defects of neonatal immunity (3438).

There are few reports on the effects of G/GM-CSF on neonatal neutrophil functions $(20-22,34,35)$. We studied the in vitro effects of CSF on neutrophil chemotaxis, polarization, and superoxide anion generation in isolated cells of neonates compared with adults. 


\section{METHODS}

The study enrolled 47 healthy full-term newborn infants from healthy nonsmoking mothers, appropriate for gestational age, after an uneventful pregnancy and delivery. The study also included 35 healthy adult volunteers. Five milliliters of venous peripheral blood were obtained from 2- to 5-d-old newborn infants and $10 \mathrm{~mL}$ were withdrawn from the adult group. Assays were performed simultaneously in neonates and adults. We tested the neutrophil random migration, chemotactic activity, polarization, and superoxide anion release before and after preincubation with colony stimulating factors. All experiments were performed in duplicates.

The Helsinki Committee at Meir General Hospital, Sapir Medical Center, Kfar Sava, Israel, approved the study, and parental signed consent was obtained.

\section{Isolation of polymorphonuclear leukocytes}

Human purified PMN (98\%) were isolated from heparinized venous blood. After sedimentation with 3\% dextran (MW 250.000; Sigma Chemical Co., St. Louis, MO, U.S.A.), the leukocyte enriched-plasma was layered on to a Ficoll-Hypaque gradient (Lymphoprep; Nycomed Pharma AS, Oslo, Norway) and centrifuged at $400 \mathrm{~g}$ for $30 \mathrm{~min}$, as previously described (39). The supernatant was discarded and the pellet was subjected to hypotonic lysis for $20 \mathrm{~s}$ to free the PMN from contaminating red blood cells. The PMN were resuspended for chemotaxis in M199 medium (Earle's salt with L-glutamine; Biologic Industries, Kibutz Beth Haemek, Israel) and for superoxide anion release and neutrophil morphology in HBSS (Sigma Chemical Co.) with $10 \mathrm{nM} \mathrm{N}$-2-hydroxyethylpiperazine- $N$ '-2-ethanesulfonic acid (HEPES; Sigma Chemical Co.).

\section{Priming neutrophils with G-CSF and GM-CSF}

Optimal dosage and time exposure of neutrophil CSF priming were previously evaluated in our laboratory for each assay and results obtained are in accordance with previous reports $(19,40,41)$. Priming for chemotaxis was done with $0.3 \mathrm{ng} / \mathrm{mL}$ $\mathrm{G}-\mathrm{CSF}$ and $0.4 \mathrm{ng} / \mathrm{mL} \mathrm{GM}-\mathrm{CSF}$, at $37^{\circ} \mathrm{C}$ for $15 \mathrm{~min}$. For polarization, priming was done with $3 \mathrm{ng} / \mathrm{mL}$ G-CSF and 1.5 $\mathrm{ng} / \mathrm{mL}$ GM-CSF, at $37^{\circ} \mathrm{C}$ for $15 \mathrm{~min}$. Priming for superoxide production was done with $10 \mathrm{ng} / \mathrm{mL}$ G-CSF and $1 \mathrm{ng} / \mathrm{mL}$ GM-CSF, at $37^{\circ} \mathrm{C}$ in $\mathrm{CO}_{2}$ environment, for $2 \mathrm{~h}$. As basal level we used medium without the addition of G/GM-CSF.

The reported therapeutic serum levels that were achieved in patients treated with G/GM-CSF are in the range of those we used in vitro for neutrophil priming $(37,42)$.

\section{Chemotaxis assay}

A 48-well chemotaxis-microchamber (Neuro Probe, Inc., Bethesda, MD, U.S.A.) was used to determine random migration and chemotaxis (43). The chemoattractant (fMLP; Sigma Chemical Co.) was suspended in the medium M199 at a concentration of $1 \mu \mathrm{M}$. Either the medium alone or the chemoattractant was added to the bottom wells. A polycarbonate membrane filter, PVP-free, with $3-\mu \mathrm{m}$ pores (Nucleopore Corp., Pleasanton, CA, U.S.A.), was placed on top of the wells in the bottom plate. The gasket and the top plate were affixed, and $50 \mu \mathrm{L}$ of $10^{6} \mathrm{PMN} / \mathrm{mL}$ were added to the upper wells. The assembly was incubated for $60 \mathrm{~min}$ in humidified air. After incubation the filter was wiped off and stained with MayGrunwald-Giemsa dye. The average number of cells in nine fields was counted under light microscopy with a $20 \times$ objective and an optical grid at $10 \times$ magnification. Net chemotaxis was calculated by subtracting the random migration from the chemotactic activity.

\section{Neutrophil morphology}

Assessment of neutrophil polarization was done according to our previous studies (7). Following priming with or without G/GM-CSF, cells of neonates and adults were stimulated by adding $100 \mathrm{nM}$ fMLP solution (final concentration). Cell morphology was captured by the addition of equal volume of ice-cold $10 \%$ formaldehyde in HBSS, supplemented with 10 nM HEPES, $\mathrm{pH}$ 7.4. The rate of polarized cells was calculated using a phase-contrast microscope.

\section{Superoxide anion release}

This assay was performed as previously reported (18). PMN $\left(10^{6}\right)$ were suspended in HBSS with $60 \mu \mathrm{M}$ of ferricytochrome C (Sigma Chemical Co.), with (control) or without $214 \mathrm{U}$ of superoxide dismutase (Sigma Chemical Co.). The rate of superoxide anion release was measured by adding $100 \mathrm{nM}$ of fMLP (Sigma Chemical Co.) for $5 \mathrm{~min}$, at $37^{\circ} \mathrm{C}$, in a UV-260 Shimadzu spectrophotometer (Kyoto, Japan), at $550 \mathrm{~nm}$. The superoxide anion release was calculated using the Massey extinction coefficient of $2.1 \times 10^{4} \mathrm{M}^{-1} \mathrm{~cm}-1$.

\section{Statistical analysis}

Mann-Whitney nonparametric test, the two-tailed $t$ test (paired or unpaired), and the GLM repeated measures procedure were used for data analysis of all leukocyte functions, where appropriate.

\section{RESULTS}

\section{Effect of G-CSF and GM-CSF on neutrophil net chemotaxis}

The results of net chemotaxis are shown in Table 1. The net neonatal chemotaxis was significantly lower than that found in adult neutrophils $(p<0.001)$. GM-CSF priming induced significant increase of net neutrophil chemotaxis of neonates $(p<$ $0.001)$ and adults $(p<0.01)$. A similar trend in the neutrophil

Table 1. Priming effect of growth factors on FMLP-stimulated neutrophil net chemotaxis (cells/field)

\begin{tabular}{cccc}
\hline & Medium & G-CSF $(0.3 \mathrm{ng} / \mathrm{mL})$ & GM-CSF $(0.4 \mathrm{ng} / \mathrm{mL})$ \\
\hline Adults & $61 \pm 4$ & $101 \pm 11^{*+}$ & $79 \pm 5^{* \dagger}$ \\
$(n)$ & $(13)$ & $(8)$ & $(10)$ \\
Neonates & $35 \pm 7 \S \dagger$ & $49 \pm 5 \dagger+$ & $55 \pm 4 \dagger+$ \\
$(n)$ & $(27)$ & $(16)$ & $(21)$ \\
\hline
\end{tabular}

Values are mean \pm standard error.

$* P<0.02 ; \dagger P<0.001$.

$\ddagger$ CSF vs medium.

$\S$ Neonates $v s$ adults. 
chemotactic activity was observed in neonates $(p<0.001)$ and adults $(p<0.02)$ following neutrophil G-CSF priming. Although neonatal chemotaxis after GM-CSF priming achieved levels similar to those found in the adult neutrophil (mean \pm SE: $55 \pm 4$ cells/field versus $61 \pm 4$ cells/field in neonates and adults, respectively, $p=0.19$ ), priming with G-CSF only reached partial correction $(49 \pm 5$ cells/field versus $61 \pm 4$ cells/field in neonates and adults, respectively, $p<0.05$ ).

It is notable that the maximal neutrophil response to cytokines was particularly observed in those newborn infants with severe impairment in their chemotactic activity. Statistical analysis of the data showed a significant inverse correlation between the basal chemotactic level and the result following CSF priming, which supported this observation $(r=-0.6, p<$ 0.02 for G-CSF; $r=-0.76 ; p<0.001$ for GM-CSF).

The random migration was not affected by the addition of CSF. GM-CSF seems to be more potent than G-CSF in neonatal cell chemotaxis, inasmuch as only the former brought about a complete recovery of the reduced neutrophil chemotaxis.

\section{Morphologic response}

Neonatal neutrophils were significantly less responsive than adult cells to optimal concentrations of $100 \mathrm{nM}$ fMLP (Table 2) $(p<0.05)$. CSF significantly increased the fMLP-stimulated polarization of both neonatal and adult cells $(p<0.05, p<$ 0.005 , respectively), blunting the differences between the basal neonatal and adult neutrophil response. CSF by themselves had a significant stimulating effect on neonatal and adult neutrophils ( $p<0.05$ and $p<0.005$, respectively).

\section{Effects of GM-CSF and G-CSF on neutrophil superoxide anion release}

Neonatal neutrophils had significantly higher fMLP-induced superoxide generation $(p<0.02)$ than adult cells, as previously reported (7).

Preexposure of neutrophils to the cytokines for $2 \mathrm{~h}$ enhanced significantly the fMLP- stimulated superoxide anion release of 14 newborn infants and 16 adult volunteers (Table 3 ). The enhancement was significantly higher using GM-CSF than G-CSF, on both adult $(p<0.001)$ and neonatal cells $(p<$ 0.05 ). For neonatal neutrophils, GM-CSF brought about an increase of $89 \%$ of superoxide production, whereas G-CSF enhanced the superoxide release by only $52 \%$. In the adult

Table 2. Priming effect of growth factors on neutrophil polarization $(\%)$

\begin{tabular}{cccc}
\hline fMLP & Medium & G-CSF $(3 \mathrm{ng} / \mathrm{mL})$ & GM-CSF $(1.5 \mathrm{ng} / \mathrm{mL})$ \\
\hline Adults $(n=9)$ & & & \\
+ & $86 \pm 2$ & $95 \pm 1 \dagger \ddagger$ & $95 \pm 1 \dagger \ddagger$ \\
- & $4 \pm 1$ & $45 \pm 6 \dagger \dagger$ & $53 \pm 5 \dagger+$ \\
Neonates $(n=6)$ & & & \\
+ & $71 \pm 5^{*} \S$ & $87 \pm 4^{*}+$ & $92 \pm 2 * \dagger$ \\
- & $4 \pm 1$ & $33 \pm 10 \dagger \dagger$ & $26 \pm 9 * \$ \S$ \\
\hline
\end{tabular}

Values are mean \pm standard error.

$* P<0.05 ; \dagger P<0.005$.

$\ddagger$ CSF vs medium.

$\S$ Neonates vs adults.
Table 3. Priming effect of growth factors on FMLP-stimulated neutrophil superoxide production (nmol $\mathrm{O}_{2}{ }^{-} / 10^{6} \mathrm{PMN} / \mathrm{min}$ )

\begin{tabular}{ccccc}
\hline & Medium & $\begin{array}{c}\text { G-CSF } \\
(10 \mathrm{ng} / \mathrm{mL})\end{array}$ & $\begin{array}{c}\text { GM-CSF } \\
(1 \mathrm{ng} / \mathrm{mL})\end{array}$ & $\begin{array}{c}P \text { value } \\
(\mathrm{G} v s \text { GM-CSF })\end{array}$ \\
\hline Adults & $1.47 \pm 0.15$ & $2.29 \pm 0.24 \dagger \dagger$ & $4.52 \pm 0.23 \dagger \dagger$ & $<0.001$ \\
$(n)$ & $(16)$ & $(7)$ & $(7)$ & \\
Neonates & $2.09 \pm 0.19 * \S$ & $3.18 \pm 0.2 * \$$ & $3.95 \pm 0.0 .36 * \dagger$ & $<0.05$ \\
& $(14)$ & $(9)$ & $(5)$ & \\
\hline
\end{tabular}

Values are mean \pm standard error.

$* P<0.01 ; \uparrow P<0.001$

$\$$ CSF vs medium.

$\S$ Neonates vs adults.

neutrophils, the effect of the CSF was more evident; the superoxide production by neutrophils increased by $207 \%$ and $56 \%$ with GM-CSF and G-CSF, respectively. GM-CSF was more potent than G-CSF in the superoxide generation, in both neonatal and adult neutrophils, a finding already reported in adult neutrophils $(19,41)$.

\section{DISCUSSION}

CSF were shown to affect in vitro functions of adult neutrophils $(15-19,40,41,44-48)$, but little information is available regarding their effect on the neonatal cells $(20-22)$. The mechanisms by which hematopoietic CSF alter PMN function are not well defined, but it has been proposed that they modulate cytoskeletal structures as well as the number and affinity of neutrophil receptors $(16,44-47)$, particularly fMLP receptors $(40,47,48)$, which mediate the functions studied here.

For normal chemotaxis the biochemical and biophysical integrity of the cytoskeleton and the cell membrane are essential $(8,47-50)$. We evaluated the effect of CSF on neonatal neutrophil chemotaxis and polarization. Our results revealed significant enhancement of the net chemotaxis of neonatal and adult neutrophils. In parallel, the PMN polarization significantly increased after CSF priming, emphasizing the close relationship between proper cytoskeleton function and optimal cell motility.

There are conflicting reports on the effect of G/GM-CSF on the adult in vitro and in vivo neutrophil chemotaxis (15); whereas some investigators reported decreased neutrophil chemotaxis following neutrophil priming with CSF in vitro (23, $28,47)$, or in vivo $(17,51)$, others have shown significant enhancement of the chemotactic activity $(19,40,52)$. In neonates few reports are available; Hill et al. reported no effect of G/GM-CSF on the neutrophil chemotaxis of three babies (20), whereas Frenck et al. found a dose-related responsesignificant enhancement of the neonatal neutrophil locomotion at low GM-CSF concentrations but inhibition at high concentrations (21). The discrepancy between the studies done in neonates and adults could reflect different priming conditions, distinct CSF dosage, and time exposure $(19,21,40)$, which were found to be critical for achieving the optimal responses $(15,40,41)$. Another aspect in neonates is the presence of neutrophil subpopulations, which could reflect different stages of maturation and thus functional responses (53-55). Supporting this neonatal cell heterogeneity, we and others found a remarkably wide range of neutrophil functions in neonates 
compared with adults $(2,7,8,53)$. Furthermore, whereas some newborns disclosed severely impaired cell chemotaxis, others showed normal activity. Hematopoietic CSF have been shown to enhance the myeloid series maturation and function (12-14) thus improving the cells' functional capability. The current study shows a significant inverse correlation between the basal chemotactic activity of neonatal neutrophils and their response to G/GM-CSF priming, possibly reflecting maturation and homogenization of the neutrophil population.

Another finding of this study is the significant enhancement of superoxide release by priming neonatal and adult neutrophils with G-CSF and GM-CSF. This positive effect of CSF on the neutrophil superoxide release is in accordance with studies done in newborn infants in vivo $(34,35)$ and in vitro $(21,34)$. In contrast in adults, although the in vitro studies showed a consistent significant enhancement of fMLP-superoxide generation following G/GM-CSF priming (16, 40, 41, 48, 56, 57), the in vivo superoxide production showed controversial results. Reevaluating the reports we found that although G-CSF administration to adult volunteers showed no effect of PMA and opsonized zymosan on superoxide release $(17,51)$, an increased neutrophil superoxide generation was achieved by fMLP stimulation (51). The improvement is probably related to the reported increased fMLP receptors' affinity $(40,48)$. Prematurity, sepsis, and stress were shown to significantly depress the respiratory burst activity of neonatal neutrophils (58); this fact emphasizes the possible advantage of G/GM-CSF administration by enhancing the respiratory oxidative burst.

Clinically, in vivo studies performed in the pediatric population $(34-38,59)$ showed that the administration of recombinant G-GM/CSF brought about a significant increase in neutrophil counts and NSP. Further, a significant reduction (61\%) in the incidence of nosocomial infections in VLBW was reported (34). Exceptionally, Schibler et al. (60) reported no effect of G-CSF administration on neutrophil counts and maturation and in the outcome of preterm and full-term septic babies. In contrast to others, these investigators pooled together preterm with full-term neonates in the analysis of the data. Moreover, while they treated septic babies with G-CSF only for $3 \mathrm{~d}$, Goldman et al. and Cairo et al. $(34,38)$ administered GM-CSF prophylaxis to VLBW infants for 28 consecutive days. Another explanation might be derived from differences in mechanisms of action of G-CSF and GM-CSF.

We found that GM-CSF was more potent than G-CSF in enhancing the neonatal and adult neutrophil functions. Other investigators also reported similar results in adults $(19,41,57)$. These cytokines differences seem to be related to different mechanisms of action $(41,57)$ and were reported to have important clinical implications $(13,19)$.

It is well known that newborn infants have an increased susceptibility to bacterial infections. The reason for that seems to be multifactorial $(2,7,8,10,11)$. G/GM-CSF, which play a major role in the regulation of the granulopoiesis, were found to be decreased in the neonate $(27,30-32)$. There is consensus about the fact that administration of hematopoietic CSF induces peripheral blood neutrophilia in several conditions (2427, 36-38). This study also shows a significant improvement of the neonatal neutrophil functions following in vitro CSF priming and contributes to a better understanding of the neonatal neutrophil behavior when treated with G/GM-CSF.

Acknowledgments. We thank Dr. Jacob Nusbacher for valuable discussions and advice during the preparation of this manuscript and to Navah Jelin, M.A., for the statistical analysis of the data.

\section{REFERENCES}

1. Greenough A 1996 Bacterial sepsis and meningitis. Semin Neonatol 1:147-159

2. Wolach B 1997 Neonatal sepsis: pathogenesis and supportive therapy. Semin Perinatol 21:28-38

3. Mease AD 1990 Tissue neutropenia: the newborn neutrophil in perspective. J Perinatol 10:55-59

4. Cairo MS, Rucker R, Bennetts GA, Hicks D, Worcester C, Amlie R, Johnson S, Katz J 1984 Improved survival of newborns receiving leukocyte transfusions for sepsis. Pediatrics 74:887-892

5. Christensen RD, Rothstein G 1980 Exhaustion of mature marrow neutrophils in neonates with sepsis. J Pediatr 96:316-318

6. Baley JE, Stork EK, Warkentin PI, Shurin SB 1988 Neonatal neutropenia. Am J Dis Child 142:1161-1166

7. Wolach B, Sonnenschein D, Gavrieli R, Chomsky O, Pomeranz A, Yuli I 1998 The neonatal neutrophil inflammatory responses: correlation of light scattering with cell polarization, chemotaxis, superoxide release and bactericidal activity. Am J Hematol $57: 8-15$

8. Wolach B, Ben Dor M, Chomsky O, Gavrieli R, Shinitzky M 1992 Improved chemotactic ability of neonatal polymorphonuclear cells induced by mild membrane rigidification. J Leukoc Biol 51:324-328

9. Wolach B, Carmi D, Gilboa S, Satar M, Segal M, Dolfin T, Schlesinger M 1994 Some aspects of the humoral immunity and the phagocytic function in newborn infants. Isr J Med Sci 30:331-335

10. Hill HR 1987 Biochemical, structural and functional abnormalities of polymorphonuclear leukocytes in the neonate. Pediatr Res 22:375-382

11. Wilson CB 1986 Immunology basis for increased susceptibility of the neonate to infection. J Pediatr 108:1-12

12. Sieff CA 1987 Hematopoietic growth factors. J Clin Invest 79:1549-1557

13. Metcalf D 1989 Hematopoietic growth factors: clinical applications. Lancet 1:885886

14. Ogawa M 1989 Effects of hematopoietic growth factors on stem cells in vitro. Hematol Oncol Clin North Am 3:453-464

15. Spiekerman K, Roesler J, Emmendoerffer A, Elsner J, Welte K 1997 Functional features of neutrophils induced by G-CSF and GM-CSF treatment: differential effects and clinical implications. Leukemia 11:466-478

16. Lopez AF, Williamson DJ, Gamble JR, Begley CG, Harian JM, Klebanoff SJ, Waltersdorph A, Wong G, Clark SC, Vadas MA 1986 Recombinant human GM-CSF stimulates in vitro mature human neutrophil and eosinophil function, surface receptor expression, and survival. J Clin Invest 78:1220-1228

17. Hoglund M, Hakansson L, Venge P 1997 Effects of in vivo administration of G-CSF on neutrophil functions in healthy volunteers. Eur J Haematol 58:195-202

18. Weisbart RH, Golde DW, Clark SC, Wong GG, Gasson JC 1985 Human granulocyte macrophage colony-stimulating factor is a neutrophil activator. Nature 314:361-363

19. Bober LA, Grace MJ, Pugliese-Sivo C, Rojas-Triana A, Waters T, Sullivad LM, Narula SK 1995 The effect of GM-CSF and G-CSF on human neutrophil function. Immunopharmacology 29:111-119

20. Hill HR, Augustine NH, Jaffe HS 1991 Human recombinant interferon $\gamma$ enhances neonatal polymorphonuclear leukocyte activation and movement, and increases free intracellular calcium. J Exp Med 173:767-770

21. Frenck RW, Buescher JES, Vadhan-Raj S 1989 The effect of recombinant human granulocyte-macrophage colony stimulating factor on in vitro cord blood granulocyte function. Ped Res 26:43-48

22. Jaswon MS, Jones HM, Linch DC 1994 The effect of recombinant human granulocyte-macrophage colony stimulating factor on the neutrophil respiratory burst in the term and preterm infant when studied in whole blood. Pediatr Res 36:623-627

23. Gasson JC, Weisbart RH, Kaufman SE, Clark SC, Hewick RM, Wong GG, Golde DW 1984 Purified human granulocyte-macrophage colony stimulating factor: direct action on neutrophils. Science 226:1339-1342

24. Segal N, Leibovitz E, Juster-Reicher A, Even-Tov S, Mogilner B, Barak Y 1998 Neutropenia complicating RH-hydrops fetalis: the effect of treatment with recombinant human granulocyte colony-stimulating factor (rhG-CSF). Pediatr Hematol Oncol 15:193-197

25. Dale DC, Bonilla MA, Davis MW, Nakanishi AM, Hammond WP, Kurtzberg J, Wang W, Jakubowski A, Winton E, Lalezari P, Robinson W, Glaspy JA, Emerson S, Gabrilove J, Vincent M, Boxer LA 1993 A randomized controlled phase III trail of recombinant human granulocyte colony-stimulating factor (filgrastim) for treatment of severe chronic neutropenia. Blood 81:2496-2502

26. Bonilla MA, Gillio AP, Ruggerio M, Kernan NA, Brochstein JA, Abboud M, Fumagalli L, Vincent M, Gabrilove JL, Welte K, Souza LM, O’Reilly RJ 1989 Effect of recombinant human granulocyte colony stimulating factor on neutropenia in patients with congenital agranulocytosis. N Engl J Med 320:1574-1580

27. Cebon J, Layton JE, Maher D, Morstyn G 1994 Endogenous haematopoietic growth factors in neutropenia and infection. Br J Haematol 86:265-274 
28. Humphreys JM, Rugman FP, Davies JM, Mimnagh P, Hart CA, Edwards SW 1991 Effect of recombinant human granulocyte colony stimulating factor on neutrophi function in vitro and in vivo following chemotherapy and autologous bone marrow transplantation. J Clin Lab Immunol 34:55-61

29. Dale DC, Liles WC, Summer WR, Nelson S 1995 Review: granulocyte colonystimulating factor-role and relationships in infectious diseases. J Infect Dis 172:1061-1075

30. Cairo MS, Suen Y, Knoppel E, Dana R, Park L, Clark S, van de Ven C, Sender L 1992 Decreased G-CSF and IL-3 production and gene expression from mononuclear cells of newborn infants. Pediatr Res 31:574-578

31. Gessler P, Kirchmann N, Kientsch-Engel R, Haas N, Lasch P, Kachel W 1993 Serum concentrations of granulocyte colony stimulating factor in healthy term and preterm neonates and in those with various diseases including bacterial infections. Blood $82: 3177-3182$

32. Bailie KE, Irvine AE, Bridges JM, McClure BG 1994 Granulocyte and granulocytemacrophage colony stimulating factors in cord and maternal serum at delivery. Pediatr Res 35:164-168

33. Wheeler JG, Huffine ME, Childress S, Sikes J 1994 Comparison of colony stimulation factors on in vitro rat and human neutrophil function. Biol Neonate 66:214-220

34. Goldman S, Ellis R, Dhar V, Cairo MS 1998 Rationale and potential use of cytokines in the prevention and treatment of neonatal sepsis. Clin Perinatol 25:699-710

35. Drossou-Agakidou V, Kanakoudi-Tsakalidou F, Sarafidis K, Taparkou A, Tzimoul V, Tsandali H, Kremenopoulus G 1998 Administration of recombinant human granulocyte-colony stimulating factor to septic neonates induces neutrophilia and enhances the neutrophil respiratory burst and the $\beta_{2}$ integrin expression. Results of a randomized controlled trial. Eur J Pediatr 157:583-588

36. Barak Y, Leibovitz E, Mogilner B, Juster-Reicher A, Amitay M, Ballin A, Koten A, Goebel M 1998 The in vivo effect of recombinant human granulocyte colony stimulating factor (rhG-CSF) in neutropenic neonates with sepsis. Eur J Pediatr 156:643-646

37. Gillain ER, Christensen RD, Suen Y, Robin E, Van de Ven C, Cairo MS 1994 A randomized, placebo-controlled trial of recombinant human granulocyte colonystimulating factor administration in newborn infants with presumed sepsis: significant induction of peripheral and bone marrow neutrophilia. Blood 84:1427-1433

38. Cairo MS, Christensen R, Sender LS, Ellis R, Rosenthal J, van de Ven C, Worcester C, Agosti JM 1995 Results of a phase I/II trial of recombinant human granulocytemacrophage colony-stimulating factor in very low birth weight neonates: significant induction of circulatory neutrophils, monocytes, platelets, and bone marrow neutrophils. Blood 86:2509-2515

39. Boyum A 1968 Isolation of mononuclear cells and granulocytes from human blood. Scand J Clin Lab Invest Suppl 21:77-89

40. Weisbart RH, Golde DW, Gasson JC 1986 Biosynthetic human GM-CSF modulates the number and affinity of neutrophil f-Met-Leu-Phe receptors. J Immunol 137:35843587

41. Sullivan GW, Carper HT, Mandell GL 1993 The effect of three human recombinant hematopoietic growth factors (granulocyte-macrophage colony-stimulating factor, granulocyte colony-stimulating factor, and interleukin-3) on phagocyte oxidative activity. Blood 81:1863-1870

42. Morstyn G, Campbell L, Lieschke G 1989 Treatment of chemotherapy-induced neutropenia by subcutaneously administrated granulocyte colony stimulating factor with optimization of dose and duration of therapy. J Clin Oncol 7:1554-1562

43. Falk W, Goodwin RH, Leonard EJ 1980 A 48-well microchemotaxis assembly for rapid and accurate measurement of leukocyte migration. J Immunol Methods 33:239247
44. Arnaout MA, Wang EA, Clark SC, Sieff A 1986 Human recombinant granulocytemacrophage colony stimulating factor increases cell-to-cell adhesion and surface expression of adhesion-promoting surface glycoproteins on mature granulocytes. $\mathrm{J}$ Clin Invest 78:597-601

45. Yong KL, Linch DC 1992 Differential effect of granulocyte and granulocytemacrophage colony-stimulating factors (G- and GM-CSF) on neutrophil adhesion in vitro and in vivo. Eur J Haematol 49:251-259

46. Weite-Owen C, Hartmann S, Alexander JW, Babcock GF 1993 Reduced PMN $\beta_{2}$ integrins after trauma: a possible role for colony-stimulating factors. Clin Exp Immunol 92:477-481

47. Atkison YH, Lopez AF, Marasco WA, Lucas CM, Wong GG, Burns GF, Vadas MA 1988 Recombinant human granulocyte-macrophage colony stimulating factor ( $\mathrm{rH}$ GM-CSF) regulates $\mathrm{f}$ Met-Leu-Phe receptors on human neutrophils. Immunology 64:519-525

48. Weisbart RH, Gasson JC, Golde DW 1989 Colony-stimulating factor and host defense. Ann Intern Med 110:297-303

49. Schmalstieg FC, Rudloff HE, Hillman GR, Anderson DC 1986 Two-dimensional and three-dimensional movement of human polymorphonuclear leukocytes: two fundamentally different mechanisms of locomotion. J Leukoc Biol 40:677-691

50. Wilkinson PC 1993 Defect of leukocyte locomotion and chemotaxis: prospects, assays, and lessons from Chediak-Higashi neutrophils. Eur J Clin Invest 23:690-692

51. Leavey PJ, Sellins KS, Thurman G, Elzi D, Hiester A, Silliman CC, Zerbe G, Cohen JJ, Ambruso DR 1998 In vivo treatment with granulocyte colony-stimulating factor results in divergent effects on neutrophil functions measured in vitro. Blood 92:43664374

52. Okuda A, Kubota M, Watanabe K, Sawada M, Koishi S, Kataoka A, Usami I, Lin YW, Furusho K 1997 Inhibition of superoxide production and chemotaxis by methotrexate in neutrophils primed by TNF- $\alpha$ or LPS. Eur J Haematol 59:142-147

53. Anderson DC, Hughes BJ, Wible LJ, Perry GJ, Smith CW, Brinkley BR 1984 Impaired mobility of neonatal PMN leukocytes: relationship to abnormalities of cell orientation and assembly of microtubules in chemotactic gradients. J Leukoc Biol $36: 1-15$

54. Arenson EB, Epstein MB, Seeger RC 1979 Monocyte subsets in neonate and children. Pediatrics 64(suppl):740-744

55. Ben-Dor M, Ashkenazi M, Wolach B 1992 Bactericidal activity of phagocytic cells in neonates. Harefuah 114:332-336

56. Burgess AW, Begley CG, Johnson GR, Lopez AF, Williamson DJ, Mermod JJ, Simpson RJ, Schmitz A, DeLamarter JF 1987 Purification and properties of bacterially synthesized human granulocyte-macrophage colony stimulating factor. Blood 69:43-51

57. Khwaja A, Carver JE, Linch DC 1992 Interactions of granulocyte-macrophage colony stimulating factor (CSF), granulocyte CSF, and tumor necrosis factor $\alpha$ in the priming of the neutrophil respiratory burst. Blood 79:745-753

58. Drossou V, Kanakoudi F, Tzimouli V, Sarafidis K, Taparkou A, Bougiouklis D, Petropoulou T, Kremenopoulos G 1997 Impact of prematurity, stress and sepsis on the neutrophil respiratory burst activity of neonates. Biol Neonate 72:201-209

59. Bracho F, Goldman S, Cairo MS 1998 Potential use of granulocyte colonystimulating factor and granulocyte-macrophage colony-stimulating factor in neonates. Curr Opin Hematol 5:215-220

60. Schibler KR, Osborne KA, Leung LY, Le TV, Baker SI, Thompson DD 1998 A randomized, placebo-controlled trial of granulocyte colony stimulating factor administration to newborn infants with neutropenia and clinical signs of early-onset sepsis. Pediatrics 102:6-12 